been found to be greater than was previously thought (Stone, Luhby, Feldman, Gordon, and Cooperman, 1967), sometimes no doubt owing to the slow return to normal of folate status following a previous pregnancy (Temperley et al., 1968). This sequence of events could occur if those patients on iron alone and with low postnatal whole blood folate levels soon became pregnant again.

\section{Conclusions}

Folate depletion in late pregnancy is again found to be common when assessed by the whole blood folate level, but only when this is tested some weeks after delivery, because of the delay in its reflection of folate status.

This depletion is prevented by the prophylactic administration of $330 \mu \mathrm{g}$. of folic acid a day, and the whole blood folate level six weeks after delivery is then close to the initial pretreatment levels in early pregnancy in this group of patients.

Though the whole blood folate is slow to reflect changes in folate status (compared with the serum level) it is a valid index of this in that a low value in early pregnancy indicates an increased liability to development of overt megaloblastic changes in late pregnancy.

We gratefully acknowledge the co-operation of Professor I. Donald, Drs. J. M. McBride, W. Barr, J. Willocks, and J. MacVicar during the conduct of this investigation, together with the help we have received from Miss McLeod and her staff in the antenatal clinic, Mr. R. Ferguson and his staff in the random allocation of patients, and Mrs. M. Shanks in the abstracting of information from case records. We are also indebted to Glaxo Ltd. for information concerning the folic acid content of Pregamal tablets.

\section{REFERENCES}

Chanarin, I., Rothman, D., Ward, A., and Perry, J. (1968). Brit. med. F., 2, 390 .

Documenta Geigy (1956). "Statistical Methods in Medicine, 5th ed., p. 31. Basle.

Hansen, H. A. (1964). On the Diagnosis of Folic Acid Deficiency. Stockholm.

Hansen, H. A. (1967). Acta obstet. gynec. scand., 46, Suppl. No. 7, p. 13.

Hansen, H. A., and Rybo, G. (1967). Acta obstet. gynec. scand., 46, Suppl. No. 7, p. 107.

Hoffbrand, A. V., Newcombe, B F. A., and Mollin, D. L. (1966). 7. clin. Path., 19, 17.

Izak, G., Rachmilewitz, M., Sadovsky, A., Bercovici, B., Aronovitch, J., and Grossowicz, N. (1961). Amer. 7. clin. Nutr, 9, 473.

Lowenstein, L., Cantlie, G., Ramos, O., and Brunton, L. (1966). Canad. med. Ass. 7., 95, 797.

Mollison, P. L. (1961). Blood Transfusion in Clinical Medicine, 3rd ed., p. 196. Oxford.

Stone, M. L., Luhby, A. L., Feldman, R., Gordon, M., and Cooperman, J. M. (1967). Amer. F. Obstet. Gynec., 99, 638.

Streiff, R. R., and Little, A. B. (1967). New Engl. 7. Med., 276, 776.

Strelling, M. K., Blackledge, G. D., Goodall, H. B., and Walker, C. H. M. (1966). Lancet, 1, 898.

Temperley, I. J., Meehan, M. J. M., and Gatenby, P. B. B. (1968). Brit. f. Haemat., 14, 13.

Varadi, S., Abbott, D., and Elwis, A. (1966). 7. clin. Path., 19, 33.

Willoughby, M. L. N. (1967). Brit. F. Haemat., 13, 503.

Willoughby, M. L. N., and Jewell, F. J. (1966). Brit. med. F., 2, 1568.

\title{
Circulatory and Metabolic Effects of Oxygen in Myocardial Infarction
}

\author{
A. C. F. KENMURE, M.B., B.SC., M.R.C.P., M.R.C.P.ED., M.R.C.P.GLASG. \\ W. R. MURDOCH, $†$ M.B., M.R.C.P., M.R.C.P.ED., M.R.C.P.GLASG. ; A. D. BEATTIE, $\ddagger$ M.B. \\ J. C. B. MARSHALL, $\S$ B.SC.; A. J. V. CAMERON,\| M.A., M.D., F.R.C.P., F.R.C.P.GLASG.
}

\begin{abstract}
Cummary: The circulatory and metabolic effects of $\checkmark$ inhalation of oxygen in high concentration were investigated in $\mathbf{5 0}$ patients with acute myocardial infarction. The heart rate, arterial blood pressure, cardiac output, blood gas tensions, $\mathrm{pH}$, and lactate and pyruvate levels were measured. In general, oxygen inhalation produced $a$ fall in cardiac output and stroke volume and a rise in blood pressure and systemic vascular resistance. In a small number of patients with very low cardiac outputs there was a rise in output. A substantial rise in arterial oxygen tension was obtained even in patients with low initial values. The raised arterial blood lactate levels which were frequently present were reduced after oxygen. The therapeutic implications of these effects are discussed.
\end{abstract}

- Senior Registrar in Medicine.

t Consultant Physician.

Research Fellow, British Heart Foundation.

Biochemist.

Consultant Physician and Cardiologist.

Cardiac Department, Western Infirmary, Glasgow W.1.

I Present address: Ballochmyle Hospital, Mauchline, Ayrshire.

\section{Introduction}

The circulatory disturbances associated with myocardial infarction have recently been the subject of several detailed studies (Broch et al., 1959 ; Malmcrona and Varnauskas, 1964 ; Thomas et al., 1965a). In addition to haemodynamic changes, one of the important findings has been a reduction in arterial oxygen tension, especially in the presence of left ventricular failure and cardiogenic shock (MacKenzie et al., 1964 ; McNicol et al., 1965 ; Valentine et al., 1966). Hypoxia may be largely responsible for some of the serious metabolic abnormalities which take place and may also contribute to the production of hypotension. Though administration of oxygen has long been recommended in the management of myocardial infarction (Dunlop and Alstead, 1966; Friedberg, 1966) there is little information available concerning its effects on the underlying circulatory derangements (MacKenzie et al., 1964 ; Thomas et al., 1965b; Cameron et al.s 1966). The object of the present investigation, therefore, was to determine the haemodynamic and metabolic effects of the administration of oxygen in high concentration to patients with myocardial infarction and to assess its therapeutic value. 


\section{Patients and Methods}

Fifty men with acute myocardial infarction were studied. Their ages ranged from 34 to 77 , with a mean of 57.6 years. The diagnosis was based on a history of cardiac pain lasting more than 30 minutes, of acute left ventricular failure, or of unconsciousness, and was confirmed by electrocardiograms which showed pathological $\mathrm{Q}$ waves and sequential ST-T-wave changes. Investigations were carried out in all cases within 24 hours of infarction, and Table I summarizes the time intervals elapsing between the onset of symptoms and the beginning of the investigations. Serial serum aspartate aminotransferase estimations were carried out and the maximum values obtained are shown in Table II.

TABLE I.-Duration of Myocardial Infarction Before Commencement of the Investigation in 50 Patients

\begin{tabular}{lll|l|l|c|c}
\hline Time (hours) & $\ldots$ & $\ldots$ & $0-6$ & $6-12$ & $12-18$ & $18-24$ \\
No. of cases & $\ldots$ &. & 38 & 6 & 4 & 2 \\
\hline
\end{tabular}

TABLE II.-Maximum Serum Aspartate Aminotransferase Levels

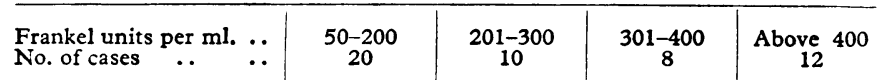

The patients were admitted to a special unit with facilities for coronary care and investigation. After initial clinical assessment, fine polyethylene catheters were introduced percutaneously under local anaesthesia into a brachial artery and antecubital vein and advanced centrally. The intravascular pressures and the electrocardiogram were monitored continuously by means of Devices strain gauge transducers and direct-writing recorder. Cardiac output was measured by a dye-dilution technique, the procedure described by Taylor and Shillingford (1959) being followed. Coomassie Blue (sodium anoxynaphthonate) was injected from a calibrated syringe, the average dose being $40 \mathrm{mg}$. The concentration of dye in the plasma was estimated by dye extraction or by a modification of the method of Deane et al. (1966). The cardiac output was measured in duplicate at each stage and the mean of the results was taken. The systemic vascular resistance was calculated from the formula:

$$
\frac{\text { Mean arterial pressure }(\mathrm{mm} . \mathrm{Hg})}{\text { Cardiac output (litres } / \mathrm{min} \text {.) }} \times 80 \text { dynes sec. } \mathrm{cm} .^{-s}
$$

Left ventricular work was determined from the formula:

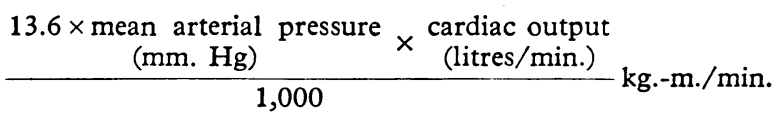

Blood gases were measured with an Instrumentation Laboratory Inc. system (Model I.L. 113). The arterial oxygen tension was measured with a Clark electrode. The carbon dioxide tension was measured with a Severinghaus electrode and the $\mathrm{pH}$ with a glass electrode. The system was calibrated with known gas samples and carefully tonometered blood. Arterial blood lactate and pyruvate levels were estimated by Boehringer enzymatic methods.

Oxygen was administered by means of a close-fitting facemask connected to a humidifier and low-resistance demand valve (McDowall et al., 1965). When oxygen is breathed this

TABLE III.-Haemodynamic Findings in 50 Patients with Acute Myocardial Infarction Breathing Air and Oxygen

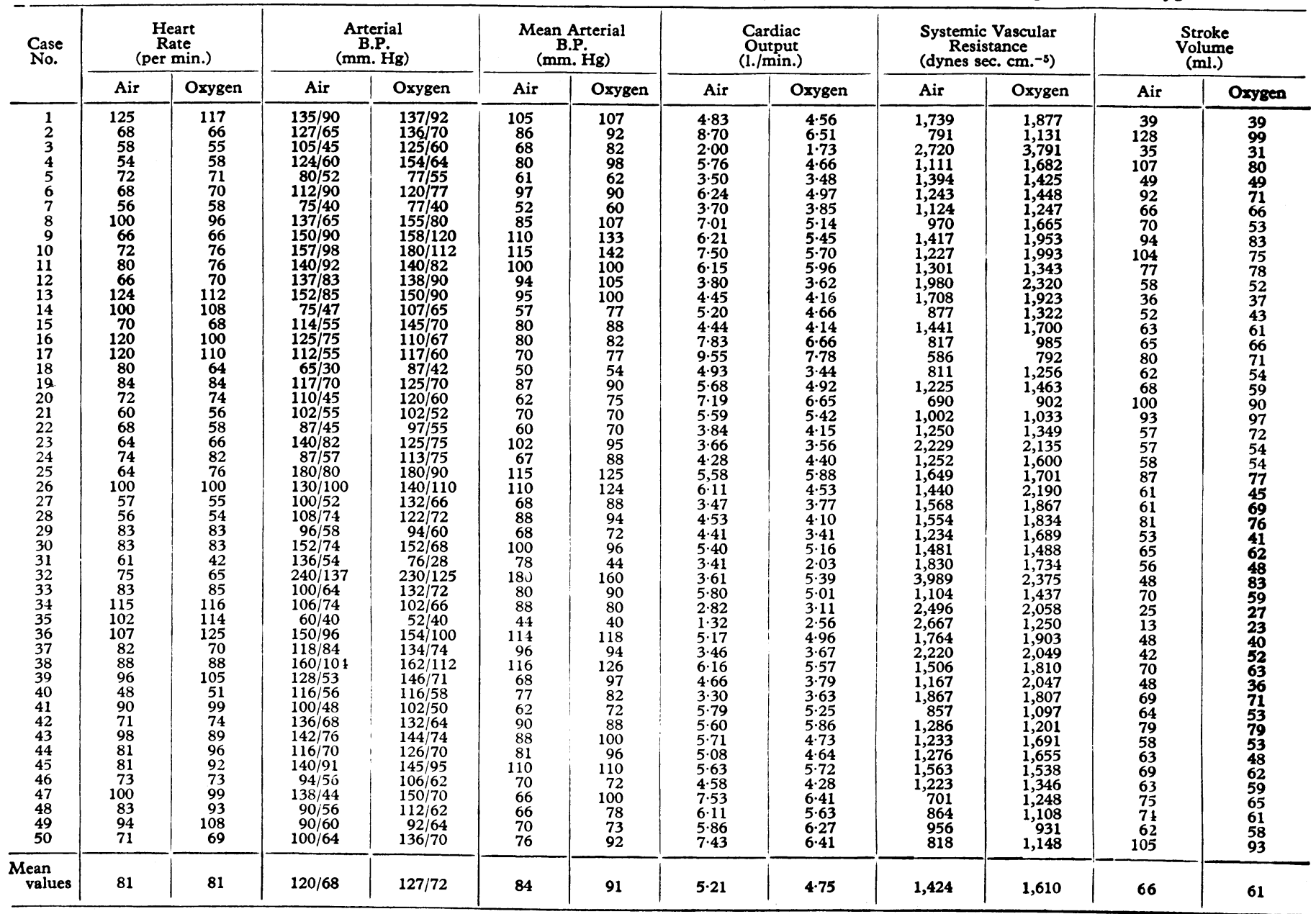


TABLE IV.-Arterial Blood Oxygen and Carbon Dioxide Tensions, $p H$, and Lactate and Pyruvate Values in 50 Patients with Myocardial Infarction Breathing Air and Oxygen

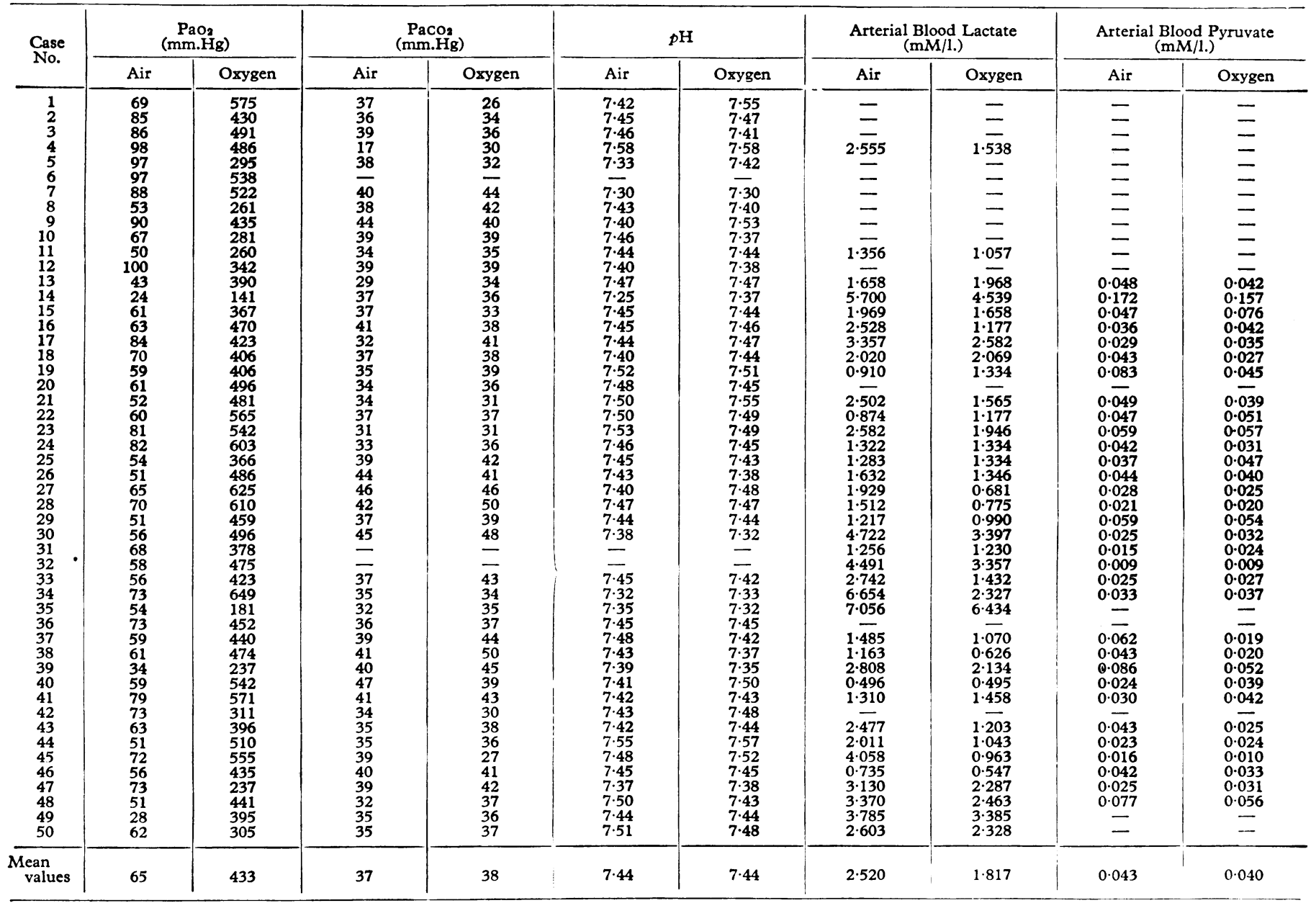

delivers a concentration of inspired gas in the region of $90 \%$ as measured by direct sampling at the mouth.

Initial observations were made with the patient breathing air. The patient was then connected to the oxygen supply and after one hour the measurements were repeated. During the investigation no drugs were required by any of the patients. After the period of study they remained in the coronary care unit for 48 hours and during this time oxygen administration was continued.

The results were treated statistically, Student's paired $t$ test and $\chi^{2}$ test being used where applicable (Fisher, 1954).

\section{Results}

The detailed haemodynamic findings and mean values in the 50 patients while breathing air and oxygen are shown in Table III and the blood gas and metabolic results in Table IV.

Heart Rate and Rhythm.-After the administration of oxygen there was a rise in heart rate in 22 patients, a fall in 21 , and no change in 7 . In the group as a whole, however, there was no significant change. Seven patients had a sinus bradycardia $(60 / \mathrm{min}$. or less $)$ on admission, and in these oxygen caused a further fall in four and a rise in the remainder. Eleven patients had a sinus tachycardia $(100 / \mathrm{min}$. or more); after oxygen there was a rise in four, a fall in six, and no change in one. Apart from extrasystoles no arrhythmia developed during the period of study.

Arterial Blood Pressure.-In 38 patients oxygen caused a rise in mean arterial blood pressure, in three there was no change, and in nine a fall occurred. The average value for the group was $84 \mathrm{~mm}$. $\mathrm{Hg}$ before oxygen, rising to $91 \mathrm{~mm}$. $\mathrm{Hg}$ after treatment $(\mathrm{P}<0.001)$. The average rise in systolic pressure was $7 \mathrm{~mm}$. $\mathrm{Hg}$ and in diastolic pressure $4 \mathrm{~mm}$. $\mathrm{Hg}$. Ten patients had a systolic pressure of $81-100 \mathrm{~mm}$. $\mathrm{Hg}$ initially, and in all but one of these the pressure increased after oxygen. A further five patients had a systolic pressure of $80 \mathrm{~mm}$. $\mathrm{Hg}$ or less; in three of these a rise occurred while in two there was a fall.

Cardiac Output.-The mean value for cardiac output while breathing air was $5.21 \mathrm{litres} / \mathrm{min}$., and after inhaiation of oxygen it fell by $0.461 . / \mathrm{min}$. to $4.751 . / \mathrm{min}$. $(P<0.001)$. In 37 patients the initial cardiac output was greater than 41 ./ min., and in 32 of these a fall occurred after oxygen; in 13 patients the cardiac output was less than $4 \mathrm{l} . / \mathrm{min}$., and in this group only five fell. The difference in response of these two groups was statistically significant $(P<0.001)$.

Stroke I'slume.-With oxygen the stroke volume fell in 34 patients, rose in 11, and was unchanged in 4 . The mean fall of $5 \mathrm{ml}$. per beat was highly significant $(\mathrm{P}<0.001)$. In 32 patients the initial stroke volume was greater than $60 \mathrm{ml}$.; in 13 it was between 40 and $60 \mathrm{ml}$., and in 5 it was less than $40 \mathrm{ml}$. Of this last group three patients showed a rise, one a fall, and one no change in stroke volume after oxygen.

Systemic Vascular Resistance.-After oxygen the systemic vascular resistance rose in 40 patients and fell in 10. For the whole group there was a mean rise of 186 dynes sec. $\mathrm{cm}^{-5}$, which was highly significant $(P<0.001)$. A raised systemic vascular resistance $\left(1,600\right.$ or more dynes sec. $\left.\mathrm{cm} .^{-5}\right)$ was present in 13 patients breathing air and in 26 after breathing oxygen. On the other hand, 12 patients had a low systemic vascular resistance initially (less than 1,000 dynes sec. $\mathrm{cm}^{-5}$ ) but only 
four after oxygen. In the group of 13 patients with a cardiac output of less than $4 \mathrm{l} . / \mathrm{min}$. a high systemic vascular resistance was present in nine, but only two of these showed a further rise with oxygen. In the other four patients of this group, who had a normal systemic vascular resistance initially, a rise occurred with oxygen.

Left Ventricular Work.-While there were some changes in the left ventricular work after oxygen in individual patients, the mean figures showed a slight fall which was not statistically significant.

Arterial Blood Gases and pH.-The arterial blood oxygen tension was reduced in 38 patients, the mean value being $65.4 \mathrm{~mm}$. Hg. After oxygen the mean value increased to 433 $\mathrm{mm}$. $\mathrm{Hg}$, a substantial rise being obtained even in those patients in whom the initial tension was very low. The arterial carbon dioxide tension was within normal limits in most patients and showed no significant change after oxygen. The mean values for $\mathrm{pH}$ were the same before and after oxygen.

Arterial Blood Lactate.-The arterial blood lactate before and after oxygen was measured in 37 patients. The level was raised in 22 patients (normal range 0.999-1.776 $\mathrm{mM} / 1$.) and after oxygen it fell in 21 of these, though in only eight did it return to normal. The fall in the mean value was significant $(P<0.001)$. While the highest levels were obtained in those patients with a very low cardiac output and arterial oxygen tension, raised values were also found in many patients who did not have marked circulatory disturbance.

Arterial Blood Pyruvate.-The arterial blood pyruvate levels were measured in 32 patients before and after oxygen. The value was raised (normal range $0.045-0.068 \mathrm{mM} / 1$.) in only four patients while breathing air, and there was no significant change after oxygen.

Mortality.-Eight patients died during the period of admission to hospital, but only two deaths (Cases 14 and 35) occurred in the first 48 hours while oxygen was being given continuously. The numbers involved are, of course, too small to allow any conclusion to be reached concerning the effect of oxygen on mortality.

\section{Discussion}

The present investigation has confirmed that in patients with myocardial infarction inhalation of oxygen in high concentration causes a small but significant drop in cardiac output and rise in arterial pressure. Since there is no alteration in heart rate the reduction in cardiac output is due to a lowered stroke volume. While the factors responsible for these changes are not fully understood, perfusion experiments on isolated segments of dog arterioles have shown that oxygen has a vasoconstrictor effect (Carrier and Guyton, 1963) and narrowing of the retinal vessels during oxygen breathing in man has been observed by Dollery et al. (1964). It therefore seems likely that the haemodynamic effects of oxygen are secondary to arterial vasoconstriction, and this concept is supported by the rise in systemic vascular resistance noted in our patients. Administration of high concentration of oxygen to healthy subjects is also associated with a reduction of cardiac output and a rise in systemic vascular resistance. In contrast to the findings in myocardial infarction, however, there is a significant fall in the heart rate which is probably mediated through the vagus with little or no change in stroke volume or arterial blood pressure (Daly and Bondurant, 1962 ; Whalen et al., 1965 ; Murdoch et al., 1968). Thus the change in cardiac output in healthy subjects is largely rate-dependent. The reason for this different response is not clear.

The therapeutic effects of these changes in patients with myocardial infarction are difficult to assess. For example, the reduction of cardiac output which is the usual response to oxygen might be undesirable and a decrease in coronary flow would be particularly disadvantageous. It is known, however, that in the oresence of myocardial ischaemia the coronary arteries are maximally dilated and blood flow is largely pressuredependent (Gorlin et al., 1959). Despite the fall in cardiac output, therefore, the accompanying rise in arterial pressure will result in improved coronary perfusion, and this is achieved without any significant increase in left ventricular work. On the other hand, in many of those patients with initially very low cardiac outputs oxygen caused a rise which could well be beneficial.

In addition to the local anoxia at the site of the infarction generalized arterial hypoxia is of ten present, even in patients in whom cardiac output and blood pressure are well maintained. With regard to this latter group the present findings confirm previous reports that correction of the hypoxaemia is usually accomplished reacily (MacKenzie et al., 1964). Moreover, with the methods of oxygen administration used in this study it has been possible to raise the arterial oxygen tension considerably in excess of normal values even in those patients with very low initial levels. However, the availability and amount of oxygen delivered to the tissue obviously depends not only on the arterial oxygen tension but also on the blood flow. Direct measurement of blood flow to individual parts of the body is difficult in severely ill patients, but indirect information regarding the adequacy of perfusion of the tissues can be obtained by study of the products of anaerobic metabolism. In any such investigation it is essential that simultaneous measurements of lactate and pyruvate levels should be made (Huckabee, 1958).

In this series a raised arterial blood lactate was a surprisingly common finding in patients with acute myocardial infarction, though the pyruvate level remained normal. While very high lactate levels were found in association with the syndrome of hypotension, hypoxia, and low cardiac output, raised values were often present in patients with less pronounced circulatory disturbances. It seems likely, therefore, that tissue hypoxia is present in many patients though it may not be clinically apparent. Inhalation of high concentrations of oxygen caused a reduction of arterial lactate levels in most cases, indicating that improved tissue oxygenation had occurred despite the reduction of cardiac output.

There are no clear indications wiether oxygen should be used routinely in the treatment of myocardial infarction. At the present time there is little available evidence from clinical trials of its effects on mortality (Cameron et al., 1965). It has been found in the present work that the blood lactate is often raised and the arterial oxygen tension reduced in acute myocardial infarction. Since these changes are indicative of tissue hypoxia, and can be at least partly corrected by the administration of high concentrations of oxygen, there may well be grounds for advocating this treatment in all patients, irrespective of the clinical severity of the illness.

We wish to thank Mrs. Norma A. Paton for technical assistance. This work was supported in part by a research award from the British Heart Foundation.

\section{REFERENCES}

Broch, O. J., Humerfelt, S., Haarstad, J., and Myhre, J. R. (1959). Amer. Heart $\not$., 57,522 .

Cameron, A. J. V., Gibb, B. H., Ledingham, I. McA., and McGuinness, J. B. (1965). Hyperbaric Oxygenation, edited by I. McA. Ledingham, p. 277. Edinburgh.

Cameron, A. J. V., Hutton, I., Kenmure, A. C. F., and Murdoch, W. R. (1966). Lancet, 2, 833 .

Carrier, O., and Guyton, A. C. (1963). Circulation, 28, 701.

Daly, W. J., and Bondurant, S. (1962). F. clin. Invest., 41, 126

Deane, B. C., Phinney, A. Ò., and McLean, C. E. (1966). F. Lab. clin. Med. 67, 177 .

Dollery, C. T., Hill, D. W., Mailer, C. M., and Ramalho, P. S. (1964). Lancet, 2, 291.

Dunlop, D., and Alstead, S. (1966). Textbook of Medical Treatment, 10 th ed., p. 586 . Edinburgh.

Fisher, R. A. (1954). Statistical Methods for Research Workers, 12th ed. Edinburgh.

Friedberg, C. K. (1966). Diseases of the Heart, 3rd ed., p. 896. Phila-

delphia and London.
Gorlin, R., Bracheld, N., MacLeod, C., and Bopp, P. (1959). Circulation, 19, 705.

Huckabee, W. E. (1958). 7. clin. Invest., 37, 244. 
McDowall, D. G., Ledingham, I. McA., Jacobson, I., and Norman, J. N. (1965). Anesthesiology, 26, 720 .

MacKenzie, G. J., Taylor, S. H., Flenley, D. C., McDonald, A. H., Staunton, H. P., and Donald, K. W. (1964). Lancet, 2, 825 .

McNicol, M. W., Kirby, B. J., Bhoola, K. D., Everest, M. E., Price, H. V., and Freedman, S. F. (1965). Brit. med. F., 2, 1270

Malmcrona, R., and Varnauskas, E. (1964). Acta med. scand., 175, 1. Murdoch, W. R., Kenmure, A. C. F., Hutton, I., and Cameron, A. J. V. (1968). In preparation.
Taylor, S. H., and Shillingford, J. P. (1959). Brit. Heart f., 21, 497. Thomas, M., Malmcrona, R., and Shillingford, J. (1965a). Circulation, 31, 811 .'

Thomas, M., Malmcrona, R., and Shillingford, J. (1965b). Brit. Heart 7., 27, 401 .

Valentine, P. A., Fluck, D. C., Mounsey, J. P. D., Reid, D., Shillingford, J. P., and Steiner, R. E.' (1966). Lancet, 2, 837.

Whalen, R. E., Saltzman, H. A., Holloway, D. H., McIntosh, H. D., Sieker, H.'O., and Brown, I. W., (1965). Amer. F. Cardiol., 15, 638.

\title{
Late Ventricular Dysrhythmias after Myocardial Infarction
}

\author{
F. H. N. SPRACKLEN, ${ }^{*}$ M.D., M.R.C.P.; E. M. M. BESTERMAN, ${ }^{*}$ M.A., M.D., F.R.C.P. \\ M. S. EVEREST,* M.B., M.R.C.P. ; J. W. LITCHFIELD,* B.M., F.R.C.P. ; M. PETRIE,* A.S.C.T.
}

Brit. med. 7., 1968, 4, 364-366

\begin{abstract}
Cummary : Serious ventricular dysrhythmias occurred in $\checkmark$ hospital after discharge from a coronary intensive care unit in 11 out of 142 patients with myocardial infarction. Previous rhythm changes, hypotension, and left ventricular failure were common findings; only one of these patients had an uneventful previous course. Four patients were resuscitated and left hospital; six were resuscitated but died at varying periods up to eight days after the event ; one patient could not be resuscitated. Recent coronary occlusion or further myocardial infarction was demonstrated in 7 of these 11 patients and presumably accounted for the dysrhythmia.
\end{abstract}

\section{Introduction}

Serious ventricular dysrhythmias may still occur after the acute phase of cardiac infarction has passed, and their cause remains undecided. These dysrhythmias could be due to persistent electrical instability of the heart muscle, or be the result of a further ischaemic episode. As this problem has obvious therapeutic consequences, an analysis was made of ventricular dysrhythmias both in and after discharge from the Coronary Care Unit of St. Mary's Hospital.

Electrocardiographic monitoring of patients has shown an incidence of $70-90 \%$ of cardiac dysrhythmias in the first 48 hours after acute myocardial infarction (Julian et al., 1964 ; Killip and Kimball, 1967 ; MacMillan et al., 1967). The increasing use of coronary care units has facilitated the recognition and correction of otherwise fatal dysrhythmias and also their prevention (Spracklen et al., 1968). In the absence of recurring or continuing complications it is unusual for patients to be kept in one of these units for more than six days (Day, 1965 ; Yu et al., 1965 ; MacMillan et al., 1967 ; Restieaux et al., 1967 ; Pentecost and Mayne, 1968 ; Thomas et al., 1968).

\section{Patients and Results}

A total of 216 patients with suspected myocardial infarction were admitted to the coronary intensive care unit between October 1966 and April 1968. Of these, 163 were subsequently shown by electrocardiographic and enzyme studies to have suffered a myocardial infarction. In the absence of significant ventricular dysrhythmias, hypotension, or cardiac failure, patients were transferred to a general ward after five days. Ventricular tachycardia occurred in 11 patients and cardiac

\footnotetext{
* Department of Cardiology, St. Mary's Hospital, London W.2.
}

arrests due to ventricular fibrillation or asystole in $27(16.6 \%)$ while in the coronary unit. Of these 27 patients, 8 could not be resuscitated, 13 were resuscitated but died later in the unit, and 6 were resuscitated successfully and discharged from the unit and the hospital. Resuscitation in this early phase was most successful in patients with a ventricular dysrhythmia occurring within 24 hours of the onset of infarction: four out of nine such cases survived to leave hospital. A total of 142 patients were discharged from the unit in a stable rhythm. Subsequent "late" cardiac arrests occurred in nine of these patients $(6.3 \%)$ while they were still in hospital. This was caused by ventricular fibrillation in eight and by asystole in one. Ventricular tachycardia occurred in a further two patients. These 11 patients were readmitted to the unit and form the basis of the present study.

\section{Readmissions to Coronary Unit}

Relevant details concerning these 11 patients are presented in the accompanying Table. The time of the so-called "late" dysrhythmias varied from 7 to 64 days after initial admission to the coronary unit. It is notable that in only one instance was the patient's previous stay in the unit entirely uneventful. Of these 11 patients the dysrhythmia was precipitated by a pulmonary embolus in one, and in seven there was subsequent evidence of a further ischaemic episode. Of the latter patients necropsy demonstrated the presence of a recent coronary occlusion by a fresh thrombus in three. In four surviving patients there was electrocardiographic and enzyme evidence of further myocardial infarction. In three patients the cause of the terminal dysrhythmia remains undecided. Enzymes were increased in all three, but this by itself may have been due to repeated attempts at resuscitation. Thus in three patients persistent electrical instability is a possible but unproved cause of the ventricular dysrhythmia, whereas in the majority it would appear that a further ischaemic episode was responsible. In only one patient (Case 8 ) was the dysrhythmia preceded by cardiac pain. Only 2 of these 11 patients were on anticoagulant drugs at the time of the dysrhythmia. Of the 131 patients who left the unit and did not have further complications during the remainder of their hospital stay 34 were on anticoagulant therapy. There were no other late hospital deaths following myocardial infarction in this series.

Non-esterified fatty acid estimations had been determined on 18 occasions in six of these "late dysrhythmic" patients during the first five days of their initial admission to the coronary unit. The first blood sample, however, was usually obtained more than 12 hours after onset of the patient's symptoms. Thus 